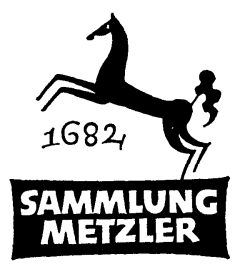

REALIENBÜCHER FÜR GERMANISTEN ABT. G: DOKUMENTATIONEN

(Reihe a: aus der Geschichte der Literaturwissenschaft und Literaturkritik) 
THEODOR WILHELM DANZEL

\title{
Zur
}

\section{Literatur und Philosophie der Goethezeit}

\author{
GESAMMELTE AUFSÄTZE \\ ZUR LITERATURWISSENSCHAFT
}

$\overline{-}$

NEU HERAUSGEGEBEN VON

HANS MAYER

MCMLXII

J. B. METZLERSCHE VERLAGSBUCHHANDLUNG STUTTGART 
ISBN 978-3-476-99230-7

ISBN 978-3-476-99229-1 (eBook)

DOI 10.1007/978-3-476-99229-1

(C)

Springer-Verlag GmbH Deutschland 1962

Ursprünglich erschienen bei J. B. Metzlersche Verlagsbuchhandlung und Carl Ernst Poeschel Verlag GmbH in Stuttgart 1962 


\section{Danzel als LiteraturhistorikeR}

\section{Von Hans Mayer}

Er wurde am 4. Februar 1818 in Hamburg geboren und starb am 9. Mai 1850 als Leipziger Privatdozent. Die Leipziger Philosophische Fakultät, die ihn fünf Jahre vorher habilitiert hatte, wurde zwar wiederholt bei der Regierung in Dresden vorstellig, um Danzels Ernennung zum Professor für Literaturgeschichte und Ästhetik zu erwirken, allein die Königl. Sächsische Regierung war von Anfang an wenig begeistert von dem zwar höchst gelehrten, aber äußerlich so gar nicht glanzvollen, überdies stets kränkelnden Privatdozenten. Nach dem Scheitern der Revolutionsbewegung von I848/49 sprach überdies noch die Freundschaft mit politisch verdächtigen Männern wie Moriz Haupt und Theodor Mommsen gegen ihn. Seine Freunde wurden schließlich wegen ihrer Tätigkeit in der Revolutionsära entlassen. Vielleicht hätte man Danzel in Ruhe gelassen, da er politisch kaum so stark hervorgetreten war wie Haupt, Отto Jahn oder die Brüder Tycho und Theodor Mommsen, aber von einer Leipziger Professur wäre nun erst recht nicht mehr die Rede gewesen.

So starb er also mit zweiunddreißig Jahren als Privatdozent. Seine Lebensgeschichte hat OTто JAHN fünf Jahre später (1 8 5 5 ) als Einleitung zu einer Ausgabe von Danzels gesammelten Aufsätzen sehr sorgfältig und liebevoll nacherzählt. Die Geschichte eines glücklosen Menschen aus bürgerlichem Hause, der unschön war, von Jugend auf kränklich, da sich schon früh das Lungenleiden ankündigte, dem er schließlich erlag. Angewiesen die vielen Jahre seines Studiums und Selbststudiums hindurch auf Zuschüsse des Vaters, die nicht immer bereitwillig gewährt wurden, zumal die Ehe der Eltern gelöst worden war. Als Danzel zwar in Leipzig habilitiert ist, aber damit rechnen muß, noch auf Jahre hinaus eine Berufung abwarten zu müssen und in der Zwischenzeit, neben Einkünften aus wissenschaft- 
licher Publizistik, auf die Zuschüsse des Vaters angewiesen zu sein, erfolgt der finanzielle Bankrott des Vaters, bald darauf dessen plötzlicher Tod im Herbst i 847. Danzel erhält nun von anderen Familienmitgliedern ein Darlehen und arbeitet so gründlich und auch erfolgreich als Essayist und Kritiker, daß er in den letzten Lebensjahren das erhaltene Geld zurückzahlen und sich etwas bequemere Lebensverhältnisse gestatten kann, die er wegen der fortschreitenden Krankheit auch sehr nötig hat. Als dann im Jahre 1849 auch noch die Mutter stirbt, mit der Danzel enger verbunden war als mit irgendeinem anderen Menschen, war seine seelische Widerstandskraft wohl erschöpft. Den ersten Band der Lessing-Biographie mit dem Titel „Gottbold Ephraim Lessing, sein Leben und seine Werke « hatte er noch vollenden können und erlebte auch noch das Erscheinen des Buches, das er aber nicht mehr, wie er gehofft hatte, der Mutter zeigen konnte. Drei Monate nach Vollendung des zweiunddreißigsten Lebensjahres starb er.

Das Lessingbuch wurde sogleich nach dem Erscheinen als große wissenschaftliche und literarische Leistung gewürdigt. In dem 1853 geschriebenen Vorwort zur Weiterführung des Lessingbuches schreibt der Nachfolger und Vollender GotTSCHALK Eduard GuHRauer, Danzel sei viel zu früh gestorben ,zur Trauer seiner Freunde und zum Verlust der Literatur und Philosophie, welche von seinen schönen reichen Kräften, nach den bereits abgelegten Leistungen, sich noch so viel versprechen konnten“". Schon die Tatsache, daß der Verleger des Lessingbuches darauf bestand, nach Danzels Tode aus dem hinterlassenen Forschungsmaterial und eigenen neuen Forschungen Guhrauers den Abschluß des Werkes zu erzwingen, zeugt für den großen Erfolg der Lessing-Monographie. Übrigens bedeutete das Lessingbuch auch für Guhrauer, einen tüchtigen Philosophen und Literarhistoriker, das Finale seiner Arbeit. Das Vorwort zum zweiten, abschließenden Band trägt das Datum des August I853. Am 5. Januar 1854 starb dann auch Guhrauer in Breslau im Alter von vierundvierzig Jahren.

Spricht man von Theodor Wilhelm Danzel, dessen Name eigentlich bloß noch der germanistischen Fachwelt vertraut ist, so meint man im allgemeinen den Lessing-Forscher. Häufig wird überdies noch erinnert, daß unter dem Titel "Gottsched 
und seine Zeit. Auszüge aus seinem Briefwechsel zusammengestellt und erläutert von $T h$.W.Danzelı im Jahre 1848 auch eine wichtige Quellensammlung zur Geschichte der deutschen Aufklärungsliteratur vom späteren Verfasser der Lessing-Monographie herausgegeben worden war, die man nicht mit Unrecht als Frucht Danzelscher Vorarbeiten zu dem Werk über Gottscheds großen Gegenspieler, den Verfasser des 17 . Literaturbriefs, anzusehen gewohnt war. Aber durch diese beiden Komplementärstudien über Gottsched und Lessing schien die Geistes- und Forschungsrichtung Danzels für die Nachwelt im wesentlichen bestimmt zu sein. Ein verspäteter Aufklärer, politisch liberal, abhold dem philosophischen Systemdenken der Hegelschule, weitgehend an monographischer Einzelforschung im Sinne des späteren Historismus interessiert, wenn man dem kurzen Vorwort zum ersten Band des Lessing folgen darf, worin es heißt: „Wenn jetzt die Zeit der Monographien im Gebiete der neuern deutschen Literaturgeschichte gekommen ist - und ich glaube, sie ist gekommen, denn an Büchern, welche eine mehr oder weniger vollständige Übersicht des Stoffes geben, ist Überfluß, und zu einer gewiegten Darstellung des mannigfach verschlungenen Entwicklungsganges fehlt es noch an der vollständigen Durchforschung des Einzelnen - so wird eine literarische Lebensbeschreibung Lessings keine der überflüssigsten und auch keine der unwürdigsten Unternehmungen sein.“

Dies alles stimmt aber nicht. Danzels Forschungsrichtung war von Anfang an gar nicht auf Lessing und Aufklärungsliteratur gerichtet, sondern auf Platon, Spinoza und Leibniz, später dann - nach dem Übergang von der Philosophiegeschichte zur Literaturgeschichte - auf Goethe und Shakespeare. Vergleicht man den Tonfall Danzels bei Darstellung Lessings mit den Akzenten der Ergriffenheit, die immer wieder auftreten, wo der Interpret über Goethe spricht, so wird man bald entdecken, daß die Lessing-Monographie bloß als nützliche Vorstufe zur eigentlichen späteren Arbeit konzipiert worden war: von einem Forscher, der aus der monographischen Arbeit eine prinzipielle Forschungsmethode zur Uberwindung aller spekulativen Literaturphilosophie zu machen gedachte. Die eigentliche Arbeit aber galt den ganz großen Gestalten: Goethe und Shakespeare, wobei eben diese Verbindung noch 
eine weitere spezifische Geisteshaltung Danzels erkennen läßt, die enge Verbindung nämlich zwischen deutscher Literatur und Weltliteratur. Danzels Interesse galt den deutschen literarischen Verhältnissen immer nur in ihrem Zusammenhang mit außerdeutschen Bewegungen. Die Deutschtümelei epigonaler Romantiker war ihm gegen Ende seines Lebens weitaus verhaßter als das wissenschaftlich nicht haltbare, durch Tatsachen nirgendwo so recht gestützte Spekulieren der ästhetischen Hegelinge.

Weil dem aber so war, sollte man die eigentliche Bedeutung Danzels für die Nachwelt gar nicht so sehr in seinen Arbeiten über Gottsched und Lessing erblicken, wenngleich das Lessingbuch auch heute noch eine bedeutende schriftstellerische und wissenschaftliche Leistung bleibt und es auch für Mut und Scharfsinn zeugte, zu einer Zeit über Gottsched zu arbeiten, wo die bloße Erwähnung dieses Namens ein allgemeines Hohngelächter hervorzurufen pflegte. Trotzdem gibt es gute Gründe für die Behauptung, Danzels eigentliches Format sei weit stärker an den scheinbaren Gelegenheitsarbeiten erkennbar, die Otto Jahn, der berühmte Mozart-Biograph und klassische Philologe, Danzels Freund in den letzten Leipziger Jahren, fünf Jahre nach dem Tode ihres Verfassers herausgab. Jahn gab sich bei Edition dieser Arbeiten, von denen einige noch ungedruckt, andere in verschiedenen Zeitschriften verstreut waren, sehr große Mühe. Der Herausgeber selbst sah sein Unternehmen weniger unter dem Aspekt einer geistigen Entdeckungsarbeit, als dem der Pietät. In dem von Lothar Wickert herausgegebenen $»$ Briefwechsel zwischen Theodor Mommsen und Otto Jahn“ (1962) schreibt Jahn aus Bonn an den Freund: „In kurzer Zeit wirst Du gesammelte Abhandlungen von Danzel bekommen mit einer biographischen Vorrede von mir; sie hat mir Not gemacht, Gott gebe, daß sie Dir und einigen wenigen gefalle“ (18. Juli I855). Mommsen antwortet bald darauf: „Deine Einleitung besonders zu unsres Danzels kleinen Arbeiten hat mir viel Freude gemacht, ihrer selbst wegen und weil es doch ein bescheidener Grabstein für vergangene Lust und vergangnes Leiden eines Kreises ist, der so nicht wieder zusammenkommt und eben darum immer zusammenhängen wird, solange noch zweie davon übrig sind. Meine Frau hat 
das auch gelesen und sich daran erfreut." Das ist alles. Ein Akt der Pietät, eine Erinnerung. Sehr nahe scheint Danzel auch dem engeren Freundeskreis nicht gestanden zu haben. Im Briefwechsel Theodor Mommsens mit seinem Bruder Tycho wird er nur - wie Professor Lothar Wickert freundlicherweise mitteilte - in einem Brief Theodor Mommsens aus Leipzig erwähnt, der kurz vor Danzels Tod geschrieben wurde (19.April I 850 ) und worin es heißt: „So habe ich hier Danzel vorgefunden, den Lessingbiographen, von dem ich Dir wohl erzählt wir gaben ihn verloren an seinem plötzlich eintretenden Lungenleiden; jetzt ist etwas Hoffnung, aber was ist das für eine Hoffnung! Sehr nah innerlich standen wir uns nicht, aber wir waren täglich zusammen und schon die gemeinsame Gewöhnung des Daseins ist ein enges Band, dessen man erst inne wird, wenn es abschnappt."

Als bloße Erinnerungsgabe war sie gedacht, aber als eigentliche Entdeckung Danzels muß die Ausgabe seiner gesammelten Aufsätze in Wirklichkeit verstanden werden. Daß Danzel, der nicht gerade brillant zu schreiben pflegte, weil aller äußerliche Glanz - übrigens auch in seinen Vorlesungen - der hanseatischen Natur widersprach, trotzdem in die Reihe großer deutscher Essayisten gehört, wurde bereits vor zwei Jahrzehnten von Oskar Loerke und Peter Suhrkamp erkannt, die den nahezu vergessenen Lessing-Forscher mit seiner Charakteristik Lessings in ihr Lesebuch aus zwei Jahrhunderten »Deutscher Geist « aufnahmen und eine kurze biographische Notiz voranstellten, die weitgehend auf Otto Jahns Vorwort zu den gesammelten Aufsätzen beruht. Auch hier jedoch spürt man Unsicherheit in der Gesamtbewertung des Schriftstellers und Essayisten Danzel, denn ein Fragment aus der Lessing-Monographie wurde für die Anthologie ausgewählt, statt einer in sich abgeschlossenen essayistischen Eigenschöpfung Danzels, woran kein Mangel war.

Erst Danzels Studien nämlich zur deutschen Klassik, zur Relation zwischen deutscher und außerdeutscher Literatur, zu den Beziehungen zwischen deutscher Philosophie und Literatur, zur Methodenlehre deutscher Literaturwissenschaft lassen das wirkliche Format und die geistigen Möglichkeiten dieses Glücklosen und Frühvollendeten erkennen. Seinen großen 
Goethe-Kommentar hat Danzel ebensowenig schreiben können wie das offenbar groß gedachte Werk über Shakespeare. Die Studien und Versuche jedoch lassen erkennen, wohin Danzel strebte, was er zeigen wollte, wie er methodisch vorzugehen gedachte. Versteht man es, diese Aufsätze, die in verschiedenen Fachorganen der Philosophie und Literaturwissenschaft, aber auch in den >Blättern für litterarische Unterhaltung` publiziert wurden, in ihrem geistigen Zusammenhang zu deuten, denn sie gehören innerlich zusammen und enthüllen nicht bloß ein geheimes geistiges Arbeitszentrum, sondern auch eine evidente wissenschaftliche Entwicklung ihres Verfassers, so entdeckt man hier den eigentlichen Danzel. Einer der ersten und bedeutendsten deutschen Literarhistoriker im Übergang von der spekulativen Literaturphilosophie zur pragmatischen Literaturwissenschaft. Eine geistige Gestalt überdies, der man nur dann wirklich gerecht wird, wenn man sie mit ihren beiden berühmteren und wohl auch glücklicheren Zeit- und Fachgenossen vergleicht: mit Gervinus und mit Hetriner.

Georg GotTfrRied Gervinus war dreizehn Jahre älter als Danzel. Als sich der Hamburger in der Mitte der vierziger Jahre von der Philosophiegeschichte abzuwenden begann, da ihm weder das Studium der Alt-Hegelianer noch die Bekanntschaft mit Arnold Ruge, den er in Halle kennengelernt hatte, einen fruchtbaren Weg für eigene weitere Forschungen zu weisen schien und es ihm offenbar auf die Nerven ging, an einer spekulativen Tagesmode beteiligt zu sein, wo jeder junge Mensch, wie Danzel gelegentlich spottet, den Wahn hegt, er habe eine ganz neue Platon-Deutung entdeckt, war Gervinus bereits ein berühmter Mann. Er hatte als Historiker begonnen, war als einer der Göttinger Sieben im Jahre I 837 abgesetzt worden, wirkte jedoch seit 1844 schon wieder als Professor in Heidelberg. Seine fünfbändige "Geschichte der poetischen $\mathrm{Na}$ tional-Literatur der Deutschen « war I 842 abgeschlossen worden. Im Todesjahr Danzels wurde auch das vierbändige Werk über "Shakespeare" vollendet, dessen Fortgang der Shakespeare-Forscher Danzel sehr aufmerksam verfolgt hatte, wie sein Aufsatz "Shakespeare und noch immer kein Ende " bezeugt.

Die Gestalt des Gervinus spielt daher in Danzels eigenen Studien mit Notwendigkeit eine gewichtige Rolle. Stets spricht 
er mit großem Respekt von dem bedeutenden Forscher; da Danzel kein Gelehrter war, der die Pose falscher Bescheidenheit vor Berühmtheiten des Tages anzunehmen pflegte, darf man annehmen, es sei ihm Ernst damit, wenn er in dem Shakespeare-Aufsatz schreibt, er hoffe immerhin, seine eigene Arbeit werde auch neben dem großen Shakespearebuch von Gervinus noch ein gewisses Interesse erregen. Andererseits spürt man immer wieder, wie sehr Danzel, bei allem Respekt vor Gervinus und seiner Begabung für literaturgeschichtliche Synthese und Epochendarstellung, der Solidität der Einzelanalysen bei Gervinus mißtraut. In Danzels Aufsatz über "Moses Mendelssobn ", der 1845 in den >Blättern für litterarische Unterhaltungく erschien, wird das Urteil des berühmten Literarhistorikers über Moses Mendelssohns angebliche philosophische Grundgedanken mitgeteilt, worauf Danzel sehr behutsam hinzusetzt: „Dies ist ein Irrtum. Man würde unrecht tun, wollte man ihn Gervinus gar zu hoch anrechnen. Die eigentlich philosophischen Schriften Mendelssohns zu lesen, lag wohl allzu sehr seitwärts von seiner Aufgabe."

Es war wohl nicht bloß das etwas unbekümmerte Manipulieren mit geschichtlichen Tatsachen bei Gervinus, was Danzels Reserve hervorrief. Weitaus stärker noch spürt man das Mißbehagen über die Politisierung, oder besser: über die ungeschichtliche Aktualisierung der Literaturgeschichte in einem Werk, das von der These ausgeht, die Zeit der großen Literatur sei mit Goethe dahingegangen, nun komme es darauf an, eine politische Wissenschaft für den Tag und für gesellschaftliche Veränderungen im Sinne des bürgerlichen Liberalismus, der nationalen Einigungsbewegung zu schaffen. Daß Gervinus die geistige und geschichtliche Entwicklung seiner Zeit selbst sehr skeptisch beurteilte, beweist sein Ausscheiden aus der Frankfurter Nationalversammlung im August 1848. In den politischen Fragen des Tages, jedenfalls in der Beurteilung der Ereignisse von 1848 , stand er daher Danzel, wie man vermuten darf, vielleicht gar nicht so fern. In den Forschungsmethoden aber bleibt Gervinus vor allem systematisierender Historiker, dem es auf Epochen und Periodisierungen ankommt, auf politische Wirkungen und aktuelle Zusammenhänge zwischen Literatur und Leben. Danzel dagegen blieb stets ein philoso- 
phierender Literarhistoriker, selbst als er sich vom Einfluß des Hegelianismus weitgehend frei gemacht hatte. Auch er suchte, wie Gervinus, das Allgemeine im Besonderen der literarischen Abläufe, aber nicht als eine allgemeine historische Gesetzlichkeit, sondern als allgemeine ästhetische Legislation. Sein sehr sorgfältiges Studium der ästhetischen Systeme seiner Zeit war organisch verbunden mit der Bemühung um wissenschaftlich genaue Interpretation der literarischen Kunstwerke nach Entstehungszeit, Anlaß, etwaiger literarischen Vorlagen.

Ein philosophierender, an den Fragen einer allgemeinen Ästhetik stark interessierter Literatur- und Kunsthistoriker war auch Hermann Hetrner. Hettner war bloß drei Jahre jünger als Danzel, aber dieser scheinbar geringe Altersunterschied vermochte in jener erstaunlichen geistigen Übergangszeit zwischen 1830 und 1848 bereits erhebliche Divergenzen bei der Behandlung philosophischer und literarischer Phänomene zu erzeugen. Für Danzel war die Schule des Hegelianismus entscheidend gewesen; auch der Arnold Ruge der >Halleschen Jahrbücher für Kunst und Wissenschaft<, dem er sich eine Zeitlang innerlich verbunden glaubte, war noch Jung-Hegelianer einer ziemlich reinen Färbung. Für Hettner dagegen steht bereits in seiner Abhandlung "Gegen die spekulative Ästhetik « von $\mathrm{r} 845$ die Kritik an Hegels philosophischem System im Mittelpunkt. In seiner Einleitung zu einer Neuausgabe von Hettners "Schriften zur Literatur" (1959) zeigt Jürgen Jahn, wie bei Hettner bereits von einem „Debüt im Zeichen Feuerbachs" gesprochen werden kann. Ludwig Feuerbachs »Kritik der Hegelschen Philosophie« von I 839 hatte die geistige Entwicklung Hermann Hettners entscheidend geprägt. Als er sich 1847 in Heidelberg habilitierte und dort, ebenso wie Danzel in Leipzig, Vorlesungen über Ästhetik und moderne Kunst und Literatur hielt, befand sich Hettner auch in enger persönlicher Verbindung mit Ludwig Feuerbach. Úbrigens auch mit Gottfried Keller vom Jahrgang I819, dessen Feuerbach-Erlebnis bekanntlich nicht bloß am »Grünen Heinrich» erkennbar bleibt, sondern immer wieder auch in den Erzählungen mitschwingt oder nachklingt. Bei Hettner bereits wird der Umschwung von der idealistischen Dialektik der Hegelia- 
ner zum Materialismus Feuerbachs (später sogar zum Materialismus Moleschotts) vollzogen. In Danzels Werken dagegen spürt man keine Spur einer Beeinflussung durch Feuerbach oder andere materialistische Gedankengänge. In seiner Abwendung von Hegel berührt er gelegentlich, wie noch zu zeigen sein wird, gewisse Gedankengänge Rankes. Aber Feuerbachianer wie Hettner oder Hebbel oder Marx, Herwegh oder Richard Wagner wurde Danzel nie.

Sehr aufschlußreich wäre ein Vergleich der Auffassungen Danzels von deutscher Klassik und Romantik, überhaupt vom Entwicklungsablauf der deutschen Literatur seit Lessing, mit Hettners 1849 geschriebenem und in Danzels Todesjahr I85o publizierten kleinem Buch über »Die romantische Schule in ihrem inneren Zusammenhange mit Goethe und Schiller«. Erst von hier aus wäre es möglich, die drei Positionen GervinusDanzel-Hettner in jener entscheidenden Phase deutscher Literaturgeschichtsschreibung genauer zu konturieren. Gegenüber Gervinus erscheint Hettner weniger unbekümmert um geschichtliche Genauigkeit. Er ist historischer und konkreter. Er ist auch keineswegs der Meinung, mit Goethes Tode sei die eigentliche Kunstperiode zu Ende gegangen. Hettner steht der Klassik wie der Romantik sehr kritisch gegenüber. Beide versteht er weitgehend als Ausdruck deutscher - gesellschaftlich ungesunder - Verhältnisse. Schiller und Kotzebue deutet er geradezu als Komplementärgestalten der gleichen Situation. Als das also, was Marx einmal in einer unmutigen Bemerkung über Schiller als „Sprung von der platten in die überschwengliche Misere" bezeichnete. Hettner hätte dieser Formulierung möglicherweise zugestimmt. Es ist daher bloß folgerichtig, wenn er sich für den Sturm und Drang und gegen die deutsche Klassik entscheidet. Dafür ist sein Urteil über die romantische Schule weitaus vorsichtiger und wohl auch gerechter. Ihre Bedeutung erblickt er vor allem in dem, was er als „Anfänge der historischen Poesie“ bezeichnet.

Danzel war es nicht mehr vergönnt, Hettners Schrift kennenzulernen. Es ist nicht daran zu zweifeln, daß er sich ausführlich mit ihr auseinandergesetzt hätte. Die Abgrenzung der Positionen war diesmal notwendiger als gegenüber Gervinus, denn Hettner stand Danzel innerlich, nicht bloß altersmäßig 
bei allen Divergenzen viel näher. Beide waren philosophische Ästhetiker, beide wesentlich interessiert an Fragen der bildenden Kunst. Beide drängten auf geschichtliche Konkretheit und Respektierung der Fakten, des geschichtlichen Details. Beide verstanden die deutsche Literaturentwicklung als ständige Beziehung zu den großen Strömungen der außerdeutschen Literatur. Was Danzel programmatisch in seiner Leipziger Stipendiatenrede "Über die Bebandlung der Gescbichte der neueren deutschen Literatur" gefordert hatte, wurde von Hermann Hettner zwanzig Jahre nach Danzels Tode (1870) in seiner umfangreichen "Literaturgeschichte des I8. Jahrhunderts « geleistet, die England, Frankreich und Deutschland in ihren Gegensätzen und Wechselwirkungen zu verstehen suchte.

Trotzdem gibt es kaum eine wirkliche Übereinstimmung der Positionen zwischen Theodor Wilhelm Danzel und Hermann Hettner. Es ist nicht bloß Feuerbach und der Materialismus. Im Jahre I 847 hatte sich Danzel höchst kritisch mit RoBERT PRUTZ und seinen damals gerade erschienenen "Vorlesungen über die Geschichte des deutschen Theaters" auseinandergesetzt. Auch Prutz war von Ruge ausgegangen und vertrat in seinen Gedichten wie Vorlesungen einen entschiedenen Vormärz-Standpunkt. Danzel nahm eine ebenso entschiedene Gegenposition ein und erklärte: „Es kommt in neuerer Zeit eine ganz neue Art von Wissenschaft auf. Früher widmete sich jeder einem Fache oder der Bearbeitung eines bestimmten Gegenstandes innerhalb desselben ganz einfach darum, weil ihn Lust und Talent auf dasselbe geführt hatte, und verfolgte dabei keinen anderen Zweck, als die Sache eben zu wissen; das rein theoretische Interesse genügte für sich selbst ohne Hinterhaltsgedanken. Das soll nun heutiges Tages nicht mehr ausreichen, und wer die Wissenschaft noch jetzt mit dieser gesunden Unmittelbarkeit betreibt, gilt für einen geistigen Zopfträger. Bloß $\mathrm{zu}$ forschen, wie es sich mit den Dingen verhalte, ist nicht mehr vornehm genug." Robert Prutz sei ein Hauptvertreter dieses Standpunkts und sein Buch werde, wie Danzel meint, ,in doppelter Weise zum Beleg dienen können, daß jene Richtung in großer Gefahr schwebt, die wahre Wissenschaftlichkeit überhaupt zu untergraben", und zwar eben in doppelter Weise: „I. daß man auch der sorgfältig ermittelten Tatsächlichkeit den 
Sinn unterschiebe, welchen sie unter der Voraussetzung, daß jene Idee die richtige wäre, haben müßte, und 2., daß man sich mit der Idee begnügt und die sorgfältige Ermittlung des Tatsächlichen überhaupt unterläßt. “ Danzel vergleicht die Fehler einer früheren bloßen Ansammlung historischer Tatsachen ohne tiefere geistige Durchdringung mit der neueren Methode von Prutz, die historischen Zusammenhänge mittels einer Idee, „über die man sich im voraus mit den Lesern verständigt“", zu interpretieren, und läßt keinen Zweifel daran, daß ihm dann die ältere Faktentreue näher steht: „Die geistlose Empirie gibt immer doch wenigstens einen authentischen Stoff an die Hand, welcher noch vergeistigt werden kann, aber das geistreiche Reden von Dingen, die gar nicht vorhanden sind, ist gar nichts nütze: ex nihilo nihil fit." Aus nichts wird nichts. Das ist Danzels Urteil über Robert Prutz und die politische Literaturgeschichtsschreibung der eigentlichen Achtundvierziger. Daß er mit dem „wahren Sozialismus" in KARL GRüNs Schrift über "Goethe vom menschlichen Standpunkter, die 1846 erschienen war, nicht glimpflicher verfuhr, war selbstverständlich. Natürlich war Hettner an Sorgfalt der Analysen und Kenntnis der geschichtlichen Zusammenhänge nicht mit Prutz oder gar mit Karl Grün zu vergleichen. Dennoch hätte Danzel im politischen Funktionsdenken Hettners vermutlich erst recht eine Forschungsrichtung erblickt, der gegenüber er möglicherweise gleichfalls geneigt gewesen wäre, einer einstigen ,geistlosen Empirie“ den Vorzug zu geben. Aber an dieser Stelle gerät die Interpretation möglicher Gegensätze zwischen Danzel und Hettner, so reizvoll sie sein mag, selbst in die Gefahr eines mehr oder weniger geistreichen Redens „,von Dingen, die gar nicht vorhanden sind".

Eines ist sicher: die Anfänge deutscher Literaturgeschichtsschreibung lassen sich nicht ohne Analyse der drei Positionen Gervinus-Danzel-Hettner darstellen. Mit der umfangmäßig schmalen Hinterlassenschaft seiner Aufsätze zur deutschen Ästhetik, Kunst- und Literaturgeschichte hat Danzel einen wichtigen Beitrag geleistet. Seine Überlegungen über Fragen der Methodologie, der Geschichtsanalyse, der Verbindung des Allgemeinen und des Besonderen im Kunstwerk sind bis in die Gegenwart hinein bedeutsam. Darüber hinaus enthalten diese 
scheinbaren Gelegenheitsarbeiten eine Fülle eindringlicher und tiefer Interpretationen deutscher Literaturentwicklung $z$ wischen 1750 und 1850 .

Danzels Studie über "Moses Mendelssobn" gehört als einzige unter seinen wichtigeren kleinen Abhandlungen zum Bereich der Aufklärungsliteratur, dem er sich in der Lessing-Monographie und der Gottsched-Edition so nachdrücklich zugewandt hatte. Den Anlaß der Rezension bildeten sieben Bände „Gesammelte Schriften" Mendelssohns, die im Jahre 1845 bei Brockhaus in Leipzig erschienen waren. Danzel nimmt seine Auseinandersetzung mit dieser Edition zum Anlaß, die Oberflächlichkeit damaliger Philosophiegeschichte zu denunzieren, welcher zwischen LEIBNIz und KANT offenbar kein Forschungsthema vorzuliegen schien. Danzel entrüstet sich: „Es ist unglaublich, wie unbekannt Moses Mendelssohn bereits geworden ist.“ Mehr noch: „Wir können wirklich von den verachteten Wolffianern immer noch einiges lernen." Hier kommt es dann zur Polemik gegen Gervinus und sein wohl kaum durch eigene Lektüre fundiertes Urteil über Christian Wolff und Moses Mendelssohn. Sehr sorgfältig arbeitet Danzel die Vorläuferschaft Mendelssohns, aber auch seine philosophischen Mißverständnisse heraus. Den Kern der Lehre Spinozas habe er mißverstanden, aber im Bereich der Ästhetik gäbe es bei Mendelssohn merkwürdige Übereinstimmungen mit Grundgedanken von Kants »Kritik der Urteilskraft«. Der Schluß der Abhandlung mit seiner Darstellung der Beziehungen zwischen Mendelssohn, Wieland und Shaftesbury hat bis heute nichts an Eindringlichkeit verloren. Hier findet sich übrigens eine bemerkenswerte Übereinstimmung mit Gedanken, die Hettner später in seiner Darstellung des deutschen 18 . Jahrhunderts entwickeln sollte.

Bei Behandlung der Frage, wer eigentlich den Spinoza richtig verstanden oder mißverstanden habe, pflegte Danzel sehr hitzig zu werden. Das gilt für den Mendelssohn-Essay von I 845, weitaus stärker aber noch für die zwei Jahre vorher erschienene Schrift, die schon im Titel das Problem SpINoza hervorgehoben hatte. Die Studie "Über Goethes Spinozismus", mit dem Untertitel " Ein Beitrag zur tieferen Würdigung des Dichters und Forschers", erschien zuerst in Hamburg bei Johann 
August Meissner im Jahre I 843 ; sie gehört zu Danzels merkwürdigsten und wichtigsten Arbeiten. Er selbst scheint, wenn man der von Otto Jahn berichteten Anekdote einigen Glauben schenkt, schon wenige Jahre später, in seiner Leipziger Zeit, der früheren Arbeit recht skeptisch gegenübergestanden zu haben. Als Jahn im Gespräch erkennen ließ, er kenne die kleine Schrift, antwortete Danzel: „Sie sind ja ein entsetzlicher Mensch! müssen Sie denn auch meine Jugendsünden kennen?“

In der Tat ist die Studie über die Bedeutung des Spinozismus für GoEthes Werk und Welt, für den Dichter und Forscher Goethe, ein typisches Werk der Übergangszeit in Danzels geistiger Entwicklung. Es ist die Untersuchung eines Philosophen, der sich ein Thema aussuchte, das ihm gleichzeitig erlaubt, seinen Neigungen zur großen Literatur nachzugehen. Die Schrift von 1843 ist aber nicht bloß insofern ein Wendepunkt in Danzels wissenschaftlicher Evolution, als hier, dem Thema nach, viel stärker als in den früheren Platon-Studien der Übergang von der philosophischen zur literaturwissenschaftlichen Thematik markiert wurde. Ausdrücklicher wird der transitorische Zustand an der wissenschaftlichen Methodik sichtbar, denn die Schrift über Goethes Spinozismus hat den Übergang zwischen spekulativer Philosophie und philologischer Akribie noch nicht gefunden. Diese Erkenntnis mochte den späteren Danzel, der sich - als Herausgeber von Gottscheds Briefwechsel und als Biograph Lessings - immer stärker den Arbeitsmethoden eines Literarhistorikers zugewandt hatte, mit einigem Unbehagen erfüllen, wenn die Rede auf das Frühwerk kam.

Eine Schrift also im Übergang von der Literaturgeschichtsphilosophie zur eigentlichen Literaturgeschichte. Eine Arbeit zudem, die immer noch stark - vielleicht weniger in der Terminologie als in der Art der Spekulation - dem Hegelianismus verbunden blieb. Die entscheidende Schwäche der bedeutenden Schrift liegt nämlich darin, daß Danzel, sehr im Gegensatz zu seiner späteren Darstellung Lessings, zwar im Verlauf seiner Schrift in recht äußerlicher Weise die verschiedenen Phasen von Goethes Entwicklung berücksichtigt, im übrigen aber Goethe gleichsam als einheitliche Gesamtgestalt zu verstehen sucht, weshalb er unbedenklich bei seinen Bemühungen, die tiefe Wesensverwandtschaft $z$ wischen Goethe und Spinoza nachzu- 
weisen, Selbstaussagen Goethes aus ganz verschiedenen Lebensaltern nebeneinander stellt. Ebensowenig scheint Danzel $z$ wischen Spinoza und dem Spinozismus sorgfältig unterscheiden zu wollen. Immer wieder bemüht er sich um den Nachweis parallelen Denkens von Spinoza und Goethe, wobei es ihn wenig zu kümmern scheint, ob Goethe die angeführten Belegstellen bei Spinoza nun wirklich kannte oder nicht. Mehr noch: auch die geschichtlichen Differenzen zwischen der SpinozaZeit und der Goethe-Zeit werden unbeachtet gelassen. Spinoza und Spinozismus scheinen für Danzel im Jahre I 843 noch eine ganz unhistorisch verstandene Einheit darzustellen, weshalb von ihm die Grundfrage seiner ganzen Arbeit, diejenige nämlich nach den Ursachen der Spinozarezeption in Goethes Dichtung und Wissenschaft, bloß zu spekulativen Betrachtungen der Hegel-Nachfolge über Wandlungen in der Auffassung von der Totalität benutzt wird.

Ganz unhistorisch geht Danzel natürlich trotzdem nicht zu Werke. Er bemüht sich zwar kaum, Spinozas Philosophie in den Zusammenhang der geistigen Auseinandersetzungen des 17. Jahrhunderts zu stellen, erst recht liegt es ihm fern, den Spinozismus mit der besonderen Situation der damaligen Niederlande in ursächlichen Zusammenhang zu bringen, aber den geschichtlichen Standort des Spinozismus im I8. Jahrhundert sucht er doch schon genauer zu bestimmen. Allerdings ist man auch hier von echter geschichtlicher Grundlegung einigermaßen weit entfernt. Danzel bleibt in seinen Bemerkungen über die geschichtliche Ausgangssituation des Goetheschen Spinozismus teilweise noch in formaler Antithetik des Hegelianismus befangen, teilweise findet man bereits gewisse Vorformen späterer geistesgeschichtlicher Betrachtung. So wird Goethes Spinozismus als dialektische Synthese in Hegels Sinne dargestellt, die es dem Denker und Forscher Goethe erlaubt habe, sowohl die These Voltaire wie die Antithese Rousseau aufzuheben. Den Gegensatz zwischen Voltaire und Rousseau sieht Danzel weder als historisches noch gar als soziologisches Phänomen (nämlich als Aufeinanderfolge von zwei Phasen der europäischen Aufklärungsbewegung), sondern als eine begriffliche Antithese. Er stützt sich hier auf den Hegelschüler KarL Rosenkranz, der Voltaire als Verfechter der Kultur in Gegensatz gebracht 
hatte zu Rousseau als Vorkämpfer der Natur. Voltaire wollte, nach Rosenkranz, die Autorität des geschichtlich Gewordenen nicht mehr anerkennen, sondern als Vorurteil mit Hilfe der Vernunft beseitigen. Rousseau aber habe gleichfalls, jedoch im Namen der natürlichen Bestimmung des Menschen, die Autorität der Geschichtlichkeit abgelehnt. Danzel modifiziert zwar in einzelnen Punkten die Urteile von Rosenkranz über den Rousseauismus, bleibt aber im Grunde der hegelianischen Antithetik trotzdem verbunden. Diese Dialektik jedoch im Verhältnis von Voltaire und Rousseau habe nun, wie Danzel darzustellen sucht, "Goethe auf die genialste Weise ganz einfach dadurch zum Abschluß gebracht, daß er die geistige Tätigkeit darauf anwies, sich selbst als jedesmalige Tatsache und die Entfaltung der inneren Natur des Menschen zu begreifen". Nur in der Selbst. verwirklichung sei die Antithetik der französischen Aufklärung überwunden: das Ideale werde zum Wirklichen, die Natur hingegen sublimiere sich, unter Preisgabe aller Gefahren der Empfindsamkeit, ,zur wahrhaft menschlichen, zur geistigen Natur“. Nun glaubt Danzel den geistesgeschichtlichen Ansatzpunkt für Goethes Spinozismus gefunden zu haben: „Dieses Erfassen des Präsenten, im höchsten Sinne des Wortes, spricht sich bei Goethe am bestimmtesten in seinem Anschluß an Spinoza aus." Danzel verweist auf Bemerkungen Goethes zu Riemer über den Einfluß der Spinoza-Lektüre von $\mathbf{1 7 8 4}$, wobei es ihn wenig zu kümmern scheint, daß die wichtigsten spinozistischen Werke des Stürmers und Drängers Goethe, das Prometheus-Fragment vor allem, bereits wesentlich früher entstanden waren. Überhaupt macht sich in Danzels Analysen die unhistorische Bemühung einigermaßen störend bemerkbar, immer wieder parallele Gedankengänge bei Spinoza und Goethe feststellen zu wollen, ohne daß der Versuch gemacht wird, reale, also nicht bloß spekulative Beziehungen aufzuzeigen.

Es kommt hinzu, daß Danzel auch die Lehre Spinozas höchst eigenwillig interpretiert. „Spinozas weltgeschichtliche Tat besteht darin, die Metaphysik unter der Form der Ethik konzipiert zu haben." Der Spinozismus Goethes aber wird dann von Danzel, läßt man viele im einzelnen nicht immer sehr klare Einzelthesen beiseite, vor allem darin gesehen, diese spinozistische Ethik ins Ästhetische transponiert zu haben: „Die 
gesuchte, dem mathematischen Verfahren Spinozas parallele Erscheinung ist die reine Kunstform der Poesie, zu welcher Goethe sich zuerst unter seinen Zeitgenossen wieder erhoben hat. “ Und weiter: „Den Gegensatz zwischen dem Natürlichen und dem Geistigen, welchen Spinoza so kräftig hervorhebt, will er mittels seiner Dichtung zu überwinden gesucht haben." Auch an dieser Stelle rächt sich in diesem bedeutenden Jugendwerk das eigentlich unhistorische Verhalten Danzels. Sonderbare Verkennung der literaturgeschichtlichen Zusammenhänge: die bedeutendste Frucht des Spinozismus findet sich zweifellos in Goethes Sturm-und-Drang-Dichtung. Danzel hingegen scheint den eigentlichen Spinozismus Goethes im wesentlichen in die Phase von Goethes klassischer Ästhetik verlegen zu wollen.

Weil es ihm darauf aber ankommt, fern aller konkret-geschichtlicher Nachweise, den Spinozismus Goethes als tiefe Wahl- und Wesensverwandtschaft darzustellen, muß er die Vermittlerrolle Herders bei allem, was mit Goethes Spinozismus zusammenhängt, in merkwürdig schroffer Weise ablehnen. Mit Goethes Straßburger Lehrmeister geht Danzel in recht hochfahrender Weise um. Wenn er Jacobi als ,eigentlichen Dilettant in der Philosophie" bezeichnet, so mag das noch angehen, wenngleich die Begründung auch hier stutzen macht: „,denn er philosophiert nicht um der Wissenschaft, sondern um des Lebens willen“. Der Spinozismus Herders aber erscheint bei Danzel als Summe von Mißverständnissen. Überhaupt wird der Schüler Hamanns und Lehrer Goethes als Gesamtgestalt erheblich reduziert. Herders religiöse und sittliche Bestrebungen sind für Danzel, der sich dabei auf Gervinus beruft, von Lavater nicht wesentlich verschieden. Dem Dichter Herder wird die „Allernährung seiner Produktion aus aller möglichen Lektüre" vorgeworfen; an Herders späterer Polemik, womit offensichtlich die Auseinandersetzung mit Kant gemeint ist, wird „der ängstliche Selbsterhaltungstrieb“ festgestellt; sein Spinozismus sei gleichzeitig Mißverständnis und eklektischer Versuch, „die Leibnizische prästabilierte Harmonie mit der substantiellen Einheit des Spinozismus zu verbinden". Danzel geht noch weiter: immer wieder scheint er bemüht, Goethe ausdrücklich gegen alle übrigen Stürmer und Dränger und Künst- 
ler der Geniezeit abzugrenzen. Die Grafen Stolberg, Klinger, Jacobi, Herder: sie alle werden von Danzel abgetan, da ihnen zwar das Streben nach Totalität innewohnte, ohne daß jedoch, wie bei Goethe, diese Totalität wirklich erreicht wurde. Die wirkliche Totalität, und damit die Transformierung der metaphysischen Ethik Spinozas in ästhetische Metaphysik, ,geschah in Goethes Poesie, in deren Geformtheit sich die durchgeführte Reflexion ausdrückt, durch welche allein eine solche Erreichung möglich wird". Worauf Danzel seine Grundthese verkünden kann: „So ist der Dichter Goethe, indem er die totale Energie des Daseins nicht mehr bloß zu theoretischer, sondern zu praktisch lebendiger Gegenwart bringt, die direkte Konsequenz des Philosophen Spinoza."

Nun wird klar, warum Danzel seiner Studie über Goethes Spinozismus den Untertitel gab: „Ein Beitrag zur tieferen Würdigung des Dichters und Forschers." Hier aber gelingt es der Studie, die elf Jahre nach Goethes Tod geschrieben wurde, weit über Rosenkranz und Gervinus hinaus, von Karl Grün ganz zu schweigen, einen wichtigen neuen Ansatz zur Beurteilung der Goetheschen Lebensleistung zu finden. Man wird zwar nicht behaupten können, Theodor Wilhelm Danzel habe in seiner Analyse der spinozistischen Elemente in Goethes Denken und Dichten eine befriedigende, historisch haltbare Darstellung gegeben. Die Forschung wandte sich bald von Danzels Idee der Annahme eines "Total-Spinozismus" bei Goethe ab. Den Ungerechtigkeiten bei Beurteilung Herders trat Bernhard Suphan im Jahre 188 I mit seiner Studie "Goethe und Spinoza 1783-1786« entgegen, wobei er jene historische Fixierung des Spinozismus vornahm, die Danzel vermissen ließ. Allein nicht in diesen Schroffheiten und spekulativen Konstruktionen liegt die eigentliche Bedeutung der bemerkenswerten Schrift des jungen Danzel für die deutsche Literaturgeschichte, sondern in der Art, wie er bemüht war, Goethes dichterisches und wissenschaftliches Bemühen als geistige Einheit zu sehen. Der von Hegel übernommene Begriff der Totalität gestattete dem angehenden Literarhistoriker, die Gesamtgestalt Goethes und die wirklichen Dimensionen seiner Lebensleistung zutreffender $\mathrm{zu}$ sehen als irgendeiner seiner Vorgänger und Zeitgenossen. Sehr fruchtbar ist daher Danzels These: „Man hat von Goethe 
gesagt, daß er auch im Wissenschaftlichen Dichter gewesen; nach dem Vorstehenden dürfen wir dies wohl einstweilen dahin umkehren, daß selbst seine Dichtung von einem wissenschaftlichen Geiste durchatmet sei." Weshalb Danzel auch als einer der ersten Goethe-Interpreten imstande war, enge Beziehungen zwischen Goethes Farbenlehre und seiner Dichtung herzustellen. Es ist dabei nicht wichtig, daß Danzel sicherlich irrt, wenn er „die Farbenlehre eine künstlerische Verarbeitung des Spinozismus" nennt. Aber er hat durchaus kühne und tiefe Erkenntnisse aufzuweisen, wenn er diese Zusammenhänge hervorhebt und bereits, wohl als frühester unter allen Zeitgenossen, erkennt, daß sich in Goethes späten "Maximen und Reflexionen " gleichsam die Synthese des Dichters und des Forschers findet.

Das Problem Goethe-Spinoza wird man anders sehen müssen als Danzel in jener Schrift von i 843. Einzelwerke und Lebensphasen Goethes hat der Interpret später selbst, als er sich immer weiter von der spekulativen Philosophie entfernt hatte, vermutlich zutreffender und genauer interpretiert. Als Gesamtdeutung aber der Goetheschen Gestalt und Lebensleistung ist jene Schrift über den Spinozismus auch von Danzel selbst nicht mehr übertroffen worden.

Die von Otto Jahn zum erstenmal nach dem Manuskript gedruckte "Einleitung zu dem Kommentar $₹ u$ Goethes Werken " war offenbar eine Arbeit aus der letzten Lebenszeit. In Leipzig hatte der junge Literaturwissenschaftler und Ästhetiker die Bekanntschaft SALOmon Hirzels gemacht, der nicht bloß eine berühmte Goethe-Bibliothek besaß, sondern die Goetheforschung auch durch sein Verlagsunternehmen zu fördern gedachte. Hirzel selbst hatte bereits im Jahre 1845 die wichtigsten Dichtungen und Briefdokumente des jungen Goethe ediert und drei Jahre später (I 848) das »Verzeichnis einer Goethe-Bibliothek « folgen lassen. Die Bekanntschaft mit Danzel, dem ungemein gedankenreichen und fleißigen Literaturwissenschaftler und Goethe-Verehrer, regte Hirzel an, dem jungen Forscher, wie Otto Jahn berichtet, den Vorschlag zu machen, „,ein exegetisches Handbuch zu Goethes Werken auszuarbeiten, welches als Supplement zu jeder Ausgabe dienen könnte". Otto Jahn präzisiert noch genauer die Aufgaben, die Danzel gestellt worden waren: ,in gedrängter Kürze das beizubringen, was zum hi- 
storischen Verständnis des Dichters erforderlich ist". Dazu gehörten Hinweise auf Werkentstehung und Anspielungen, auf Persönlichkeiten und Zeitverhältnisse, nicht zuletzt genauere Auskünfte über Versionen und Textvarianten.

Zur Ausführung dieses großen Plans, der in Danzel sicherlich einen hervorragenden Bearbeiter gefunden hätte, ist es dann nicht mehr gekommen. Der Beauftragte steckte inzwischen wohl auch zu stark in der Lessingarbeit. Das erhaltene Manuskript seiner Einleitung jedoch gibt Aufschluß über Geist und Technik der geplanten Unternehmung. Danzel stellt gleich zu Beginn seiner Introduktion ein methodisches Postulat auf, das für alle Editionsprobleme unserer Tage noch nichts an Gültigkeit verloren hat. Er betont nämlich, die kritische Edition von Werken eines zeitgenössischen Autors müsse nach ganz anderen Prinzipien verfahren, als sie bei Herausgabe eines Werkes der griechischen und römischen Literatur durch einen klassischen Philologen zu gelten hätten. Diese nämlich, meint Danzel, „müssen uns das Werk erst sprachlich und sachlich erläutern, ehe sie uns das geistige Verständnis desselben erschließen können“. Worauf er fortfährt: „Bei einem vaterländischen Dichter unserer Zeit ist es damit ganz anders. Hier kann es nicht erst darauf ankommen, nur erst ein gemeines Sach- und Wortverständnis zu eröffnen; wo sollte man anfangen, wenn man sich darauf einlassen wollte; eine entlegene Anspielung mag durch eine Notiz erläutert werden, aber im allgemeinen muß das, was man Bildung nennt und was zwar niemand im bestimmten Falle so recht definieren kann, aber jeder aus eigenem Besitze kennen muß, so wie die Sprache ohnehin, vorausgesetzt werden, und so hat es denn hier der Erklärer wirklich mit dem Dichterwerke als solchem zu tun."

Der Exeget rechnet allerdings sogleich mit dem Einwand, ein exegetisches Handbuch sei eigentlich nicht mehr nötig, wenn so überaus großes Vertrauen in den Bildungsbesitz des Lesers gesetzt werde. Trotzdem sei auch unter solchen Voraussetzungen viel Anlaß zur Kommentierung gegeben, entgegnet Danzel. Es komme darauf an, zum Verständnis des zu erläuternden Kunstwerks dadurch beizutragen, daß man dessen Entstehungsprozeß ,,auf eine gewisse Weise“ als Interpret nachzuleben verstehe. Darüber hinaus aber sei am Kunstwerk sicht- 
bar zu machen, was Danzel mit dem Wort „Gestalt" bezeichnet und was wir heute eher als „Struktur“"verstehen würden. Am Beispiel eines Goethegedichtes versucht der Interpret zu erläutern, was er sich bei seinen künftigen Exegesen und Kommentaren vorgenommen habe. Jedes Gedicht Goethes sei nach dessen eigenen Worten als „Gelegenheitsdichtung“ zu verstehen: mithin müsse man diesem konkreten Entstehungsprozeß, der Gelegenheit also, als Forscher mit aller Gewissenhaftigkeit nachgehen. Hier war Danzel wohl der erste, der sich in der deutschen Literaturwissenschaft, mit Dilthey zu sprechen, um die Zusammenhänge zwischen „Erlebnis und Dichtung“ bemühte. Da jedoch Theodor Wilhelm Danzel noch aus der Schule des philosophischen Idealismus kam, folglich weit davon entfernt war, Philosophie durch Psychologie zu ersetzen, gedachte er bei solcher Interpretation des Werkes aus dem Erlebnis nicht stehen zu bleiben. Zwar sei Goethe, wie er meint, „ohne allen Zweifel von allen Dichtern, die jemals gelebt haben, der individuellste“ gewesen. Er habe nur erlebte Situationen zu schildern verstanden, ohne sich dadurch zu behelfen, daß er denkbare, aber nicht erlebte Situationen „,in sich zu reproduzieren gewußt habe"; wodurch sich Goethe, nach Ansicht Danzels, von Schiller wie von Shakespeare unterscheide. Der Interpret geht sogar so weit, Goethes »Wilhelm Meister" und »Faust" als „wirkliche Biographien“" zu charakterisieren.

Trotzdem sei Goethes Dichtung allenthalben, nicht bloß also in der Lyrik, weit mehr als Gelegenheitsdichtung. Hinter jedem noch so individuellen Erlebnis stehe eine Gesetzmäßigkeit, die sich im konkreten Phänomen manifestiere. Mit Goethes Erlebnissen verhalte es sich nicht anders. Die poetische Größe aber des »Faust«-Dichters habe darin bestanden, diese Gesetzmäßigkeit nicht bloß jeweils verstanden, sondern auch zur gültigen Form gebracht zu haben. Um diesen merkwürdigen und tiefen Gedanken zu erläutern, bedient sich Danzel eines interessanten Vergleichs aus dem Alltagsleben. Er weist darauf hin, daß durchaus zufällige Ereignisse im Leben, die scheinbar vor allem von subjektiven Entscheidungen der Individuen abhängig seien, „gerade auf die strengste Weise unter der Herrschaft einer geheimen Gesetzmäßigkeit" ständen: die Statistik bringe es an den Tag. Bei aller Individualität und Subjektivität gäbe 
es exakte Kurven, die den Ablauf von Geburt und Tod zu registrieren wüßten. In Weiterführung dieser Gedanken, die hier bei Danzel auftauchen, hat sich bekanntlich die positivistische Soziologie in Frankreich gegen Ende des 19. Jahrhunderts darum bemüht, eine scheinbar höchst subjektive und individuelle Entscheidung wie den Selbstmord zum Gegenstand wissenschaftlich-gesetzmäßiger Untersuchung zu machen, worin gezeigt wird, welche Jahreszeiten, ökonomischen Verhältnisse, Wochentage, klimatischen Zustände, Alterslagen der Verlockung des Freitods besonders stark ausgesetzt sind. Die individuelle Entscheidung eines Freitods als Bestätigung soziologischer Gesetzeserforschung.

Eben dies meint Danzel, wenn er die enge Verbindung zwischen Erlebnis und Dichtung, individueller Gelegenheit und poetischer Struktur am Beispiel Goethes darzulegen bemüht ist. Goethe versuche in jedem Kunstwerk nicht bloß die Gelegenheit zu gestalten, in der es entstand, sondern dieser $\mathrm{Ge}-$ legenheitsdichtung auch eine Form zu geben, die geschichtlich tradiert, also traditionsgebunden ist. Daraus erkläre es sich, daß man höchst geistloser Weise, wie Danzel rügt, die Dichtung Goethes bald als bloße Nachahmung früherer Kunst, bald als Imitation derWirklichkeit mißverstanden habe. Ihre Bedeutung liege aber gerade in der Verbindung dieser beiden Elemente: der unlöslichen Verschränkung von vorgeprägter Form und konkretem Erlebnis. Daß der Exeget und Interpret Danzel hier ein weit tieferes Verständnis Goethescher Dichtung offenbart als nahezu alle Zeitgenossen, ist heute evident. Im Grunde versteht Danzel die Kunstwerke Goethes durchaus in jenem Sinne, den der Dichter selbst in seinem Aufsatz über "Einfache Nachahmung der Natur, Manier, Stil« aus dem Jahre 1789 erläutert hatte: daß im Begriff des „Stils" sowohl die bloße Imitation der Natur wie die bloß subjektivistische Manier einer individuellen Begabung zur höheren Einheit geführt werde. Es bleibt, betrachtet man das Versprechen dieser Einleitung zu einem Goethe-Kommentar, ein großer Verlust, daß es Danzel nicht mehr vergönnt war, dies tiefe und authentische Deutungsprinzip auf die Hauptwerke Goethes anzuwenden.

Vor allem die Gedanken zu "Clavigo«, in gewisser Hinsicht auch die paar Seiten über "Iphigenie« in ihrem Verhältnis zu 
Diderot, lassen ahnen, was von Danzels Goethe-Interpretation zu erhoffen war. Der von Otto Jahn zum erstenmal gedruckte Aufsatz "Über Goethes Clavigo" (Danzel schreibt „Clavijo“, weil José Clavijo y Fayardo die historische Vorlage der Dramengestalt abgegeben hat) gehört zu den bedeutendsten Interpretationen deutscher Dramatik im 19. Jahrhundert und läßt sich an Tiefe des dramaturgischen Verständnisses und Genauigkeit der Interpretation durchaus mit Ludwig Börnes berühmter Kritik von "Wilhelm Tell « oder mit Friedrich Hebbels Analyse von Kleists »Prinz von Homburg« vergleichen. Dem Programm entsprechend, das er sich für seine spätere umfassende Goethe-Interpretation gestellt hatte, geht Danzel abermals vom Verhältnis zwischen Stoffvorlage und dichterischer Form aus. Er schildert sehr exakt die spanische Affäre Beaumarchais' mit José Clavijo, dem treulosen Verführer seiner Schwester, so wie sie der spätere Dichter des "Figaro « selbst in einem "Mémoire» dargestellt hatte, das Goethe den Anstoß zur dramatischen Gestaltung gab. Ausführlich wird dargestellt, warum die Gestalt des Beaumarchais bei der dramatischen Transponierung zurücktreten, während die im historischen Zusammenhang ziemlich belanglose Figur der Marie an tragischer Bedeutung gewinnen mußte. Der historische Clavijo, von Beaumarchais bloß unter den Aspekten eines Ehrenhandels und, aus begreiflichen Gründen, als ziemlich verächtlich dargestellt, mußte bei Goethe aus dieser Sphäre des Schurkenhaften und Feigen herausgehoben werden, da sonst, wenn sie einem jämmerlichen Menschen galt, die Liebe der Marie zu Clavigo vom Zuschauer und Leser nicht als tragisches Motiv empfunden werden konnte. Ergreifend übrigens, wenn der schwer lungenkranke Danzel betont, die Krankheit der Marie in Goethes Schauspiel habe in einem Herzleiden bestanden: ,die Schwindsucht, von der Carlos redet, wird von ihm erdichtet, um den physischen Widerwillen, den dem Manne ein solches Leiden bei dem Frauenzimmer, mit dem er sich nahe zu verbinden im Begriffe steht, einflößen muß, im Clavijo hervorzurufen".

Allenthalben ist der Interpret um Verständnis für die Konflikte der Gestalten bemüht. Clavigo durchlebt einen echten Zwiespalt zwischen früheren Verpflichtungen und späteren gesellschaftlichen Erfahrungen. Aber auch Carlos sei keineswegs 
ein Schurke der üblichen Dramentradition vor Goethe; im Gegenteil habe der Dichter bei dieser Figur ausdrücklich ,,in Carlos den reinen Weltverstand mit wahrer Freundschaft gegen Leidenschaft, Neigung und äußere Bedrängnis wirken lassen, um auch einmal auf diese Weise eine Tragödie zu motivieren“. Man kann es noch anders sagen: Carlos ist durchaus kein Marinelli, wenngleich er bei Theateraufführungen des "Clavigo« gern in ähnlicher Weise dargestellt zu werden pflegt.

Noch eine weitere kluge Beobachtung Danzels zur Interpretation des Titelhelden wird angeschlossen. Die Schwäche Clavigos sei nichts anderes „als ein Überwiegen des ästhetischen Vermögens". Clavigo sei Schriftsteller, leite eine Wochenschrift im Stil des r8. Jahrhunderts, sei daher empfänglich für neue Eindrücke, könne sich geistig und seelisch in jede neue und bedeutsame Lage versenken, um sie ganz zu durchleben: ,lauter notwendige Eigenschaften für den Dichter, die aber, wenn sie ins Leben übertragen werden, eine ganz unmännliche Veränderlichkeit hervorrufen müssen".

Liest man die Anmerkungen Danzels über Clavigos Charakter, so wirken sie wie eine Vorwegnahme der offenbar geplanten, aber nicht mehr ausgeführten Charakteristik des »Torquato Tasso«. Auch die Art, wie Danzel den Carlos interpretiert, mutet wie eine Vorform zu einer künftigen Deutung des Antonio an. Daß sich der Interpret der Beziehungen des Clavigothemas zur Sesenheimer Episode bewußt ist, daß hinter der Figur des Carlos, der Freundschaft und Weltverstand miteinander vereinigen möchte, die Züge des Goethefreundes Merck sichtbar werden, läßt erkennen, wie auch dieser »Clavigo «-Aufsatz im Zusammenhang einer umfassenden Goethedeutung konzipiert worden war, bei welcher die Analyse des Clavigo bereits im Hinblick auf künftige Deutungen von Tasso und Faust angelegt wurde.

Gegenüber dem Clavigo-Aufsatz sind die paar Seiten über "Goethes Iphigenie und Diderot" eher als notwendige Vorarbeit für eine tiefer eindringende Analyse der »Iphigenie auf Tauris« anzusehen. Wie bei der Interpretation des »Clavigo « geht Danzel auch diesmal vom Verhältnis Goethes zu seinem vorgeformten Stoff aus, um durch Vergleich die eigentümlichen neuen Qualitäten der Goetheschen Dichtung sichtbar zu machen. Er 
spricht zunächst über die Bedeutung der berühmten Korrespondenz des Barons Grimm für das Aufklärungsdenken, insbesondere für die Verbreitung der Gedanken DIDERots, und kommt dann auf den Jahrgang 1757 der Korrespondenz zu sprechen, der in seiner Nummer vom $\mathrm{I}$. August einige $\gg \mathrm{Ob}$ servations de Mr. Diderot sur l'Iphigénie« enthielt. Den Anlaß für Diderots Bemerkungen zum Thema der "Iphigenie« bot das inzwischen vergessene Schauspiel eines südfranzösischen Dramatikers. Die von Danzel wiedergegebenen Gedanken Diderots sind interessant und wirken in der Tat, worauf es dem Zitierenden vor allem ankam, wie ein erstes Konzept der »Iphigenie auf Tauris«. Diderot beklagt, daß in den bisherigen Dramatisierungen der tauridischen Iphigenie seit Euripides die Gestalt des Königs Thoas stets belanglos bleibe: man solle das Volk der Taurier statt dessen auf die Szene bringen. Auch bedeute es einen eigentümlichen Bruch in der Figur der Iphigenie, wenn sie, die seit Jahren ungerührt ihre Menschenopfer vollzog, nun plötzlich unfähig werde, ihr Amt weiter zu verrichten, da sie Griechen vor sich sieht, Landsleute also. Diderot meint, hier müsse die Erkennungsszene im Vordergrund stehen. $\mathrm{Da} ß$ die neuen Fremdlinge und Opfer als griechische Landsleute der Iphigenie auftreten, besage noch wenig; erst da sie ihren eigenen Bruder als mögliches Opfer erkennen muß, kann eine Wandlung im Verhalten möglich sein.

Danzel nimmt nicht an, Goethe habe jenes von Diderot rezensierte Schauspiel des Herrn Guymond de la Touche gekannt, hält es aber für durchaus möglich, daß Goethe in Weimar die Korrespondenz des Barons Grimm und damit die Bemerkungen Diderots über Iphigenie zu einer Zeit las, da er selbst mit dem gleichen Stoff in Gedanken umging. Zeugnisse der Beschäftigung mit dem Iphigenienstoff sind $z$ war erst seit 1779 überliefert, allein Danzel hat durchaus nicht unrecht, wenn er eine nachträgliche Lektüre von Grimms »Correspendanze littéraire, philosophique etc.« durch Goethe für möglich hält. Die Bände waren in Weimar vorhanden, Goethes Interesse an allem, was Diderot schrieb, ist genugsam bezeugt, die Übereinstimmung der Iphigenien-Konzeption des französischen Enzyklopädisten mit einigen Grundüberlegungen Goethes ist evident. Die entscheidende Folgerung nämlich, auf die es Danzel mit 
Recht ankam, besteht darin, daß Goethe - ob er nun Diderots Überlegungen nachvollzog oder nicht - eine Humanisierung der tauridischen Priesterin dadurch vornehmen mußte, daß er sie von der Last der Menschenopfer freimachte. Im Gegensatz $\mathrm{zu}$ aller früheren Tradition hat Goethes Iphigenie die Menschenopfer nicht vollzogen, sondern verhindert. Das Volk von Tauris kommt zwar bei Goethe nicht auf die Bühne, wie Diderot gefordert hatte, aber die Gestalt des Thoas ist durch sein Werben um die Priesterin weitaus verständlicher und menschlicher geworden. Auch die Gefahr allerdings, die durch seinen Zorn heraufbeschworen werden kann, wurde dadurch gesteigert.

Danzel freilich möchte noch weiter gehen und den Einfluß Diderots beim Entstehungsprozeß der Iphigenie dadurch steigern, daß er unter Berufung auf eine andere Bemerkung Diderots in Grimms literarischer Zeitschrift (denn die Korrespondenz war eigentlich eine Zeitschrift) sogar Goethes ursprüngliche Prosafassung erklären möchte. Hier freilich scheint sich der Literarhistoriker Danzel in ein freies, historisch nicht gesichertes Assoziieren zu verlieren. Richardson und Diderot: die Forderung des Franzosen, eines erbitterten Gegners der Verstragödien in Alexandrinern, antike Stoffe von nun an in Prosa umzuschreiben. Bekanntlich wurde Goethe durch Wielands Forderung einer neuen deutschen Verstragödie, durch Kritiken Herders, vor allem durch eigene tiefe Unzufriedenheit mit der Prosafassung dazu gebracht, der »Iphigenie auf Tauris« ihre endgültige Form zu geben.

Soll man daraus folgern, Goethe habe beim Schreiben seines Schauspiels als Anhänger Diderots begonnen, um sich dann den ästhetischen Forderungen Wielands anzupassen? Die etwas kühnen Thesen Theodor Wilhelm Danzels möchten es so darstellen. Man wird Zweifel äußern dürfen, ohne aber leugnen zu wollen, daß auch diese knappe Studie für den Literaturkenner und Kritiker zeugt, der sie im Jahre 1848 in den >Blättern für literarische Unterhaltung، erscheinen ließ.

Die in den gleichen Blättern zwei Jahre vorher (1846) veröffentlichte Untersuchung über "Goethe und die Weimarischen Kunstfreunde in ibrem Verbältnis ₹u Winckelmann " gehört zu Danzels bedeutsamsten Arbeiten. Sie zeigt ihn übrigens gegenüber 
der drei Jahre vorher verfaßten Schrift zum Spinozismusproblem sowohl in voller Emanzipation von der spekulativen Literarphilosophie der Hegelianer wie auch in größerer Distanz zu Goethe selbst. Der Grundgedanke seiner Schrift über Goethes Spinozismus, der von einer tiefen Wesensverwandtschaft zwischen Goethe und Spinoza ausging, hatte in Goethe die Vollendung und Synthese des Voltairianismus wie des Rousseauismus zu erblicken geglaubt. Auch diesmal geht Danzel natürlich, da es sich um WINCKELMANN handelt, auf die ästhetischen Auseinandersetzungen des I8. Jahrhunderts zurück, aber es liegt diesmal eine starke historische Kritik bereits in der These des neuen Aufsatzes, Goethe gehöre eigentlich ins 18. Jahrhundert und sei als dessen geistiger Vollender anzusprechen. In der Einleitung zu dem geplanten exegetischen Goethe-Kommentar, die aus Danzels letzter Lebenszeit stammt, wird man eine historisch gerechtere Bewertung des Zeitlichen und des Überzeitlichen bei Goethe erblicken dürfen.

Fast unmutig debütiert Danzels Aufsatz mit ein paar herablassenden Bemerkungen über RIEMER, dessen 1846 erschienener Band "Briefe von und an Goethe" den Anlaß zu Danzels Aufsatz abgegeben hatte. Scheinbar schreibt Danzel eine Rezension dieser Briefausgabe, macht sich aber ziemlich rasch von diesem Anlaß frei, um das eigentliche Thema seiner Studie erklingen zu lassen: die Beziehungen zwischen Goethes Dichtung und seiner Auffassung von der bildenden Kunst. Da in Riemers Briefsammlung die Korrespondenz zwischen GoEthe und Heinrich MeYer im Mittelpunkt stand, bot sich für Danzel eine günstige Gelegenheit, die Grundprinzipien der Goetheschen Theorie bildender Künste in ihrer Bedeutung für seine Dichtung zu untersuchen. Der Anlaß der Rezension wird rasch abgetan: dem Kritiker Danzel scheint Riemers Literatur der Goethe-Pietät auf die Nerven zu gehen; Friedrich Wilhelm Riemer wird recht gönnerhaft von dem damals achtundzwanzigjährigen Rezensenten als „,verdienter Mann“ apostrophiert; in der umfangreichen Studie finden sich zwar zahlreiche gut ausgewählte Goethe-Zitate, aber sie werden eigentlich kaum in dem Briefband gesucht, der rezensiert werden soll.

Danzels Gereiztheit gegen Riemer und die bloße GoetheApologetik erklärt sich insgeheim wohl durch die neue histo- 
rische Betrachtungsweise, die er sich damals gerade zu erarbeiten bemühte. Der Hegelianismus scheint abgetan; der Betrachter drängt bei sich und jenen Autoren, die er nun kritisiert, auf geschichtliche Konkretheit. Auch Goethe dürfe nicht mehr bloßer Gegenstand der Bewunderung und Einfühlung bleiben: „Es braucht keine Mißachtung seiner Größe daraus hervorzugehen, wenn er uns noch mehr historisch werden wird; im Gegenteil wird seine Anerkennung dadurch in mancher Beziehung wieder hergestellt werden." Das Prinzip der Geschichtlichkeit wird sehr nachdrücklich vertreten. Goethe solle in geschichtlicher Situierung gezeigt werden und zwar weitgehend als Phänomen des I 8. Jahrhunderts. Auch seine Theorie der bildenden Kunst müsse entsprechend historisch verstanden werden. Ihre historische Begrenztheit, damit aber auch ihre ästhetische Unergiebigkeit, erkläre sich daraus, daß sie, indem sieWINC KELMANN zu folgen beschloß, ihrerseits unhistorisch zu Werke ging und die Antike in durchaus ungeschichtlicher Weise absolut zu setzen suchte. „Und daraus ergibt sich ganz unmittelbar bei Winckelmann eine Anschauungsweise, die man als durchaus unhistorisch bezeichnen muß, nämlich daß die Kunst nur unter dem Gesichtspunkte ihres Wachstums und ihrer Abnahme betrachtet wird, da doch in der Geschichte nichts eine bloßeVorbereitung $\mathrm{zu}$ etwas anderem oder eine bloße Nachwirkung von etwas anderem sein kann, sondern alles eine positive Bedeutung haben, etwas für sich selbst Geltendes sein muß.“

Dies ist ein sehr merkwürdiges Zitat. Bei einem Allesleser wie Danzel darf getrost angenommen werden, daß er auch RANKES > Historisch-politische Zeitschrift $<$ von $1832-1836$ studiert hatte und dabei auf das »Politische Gespräch» von 1836 gestoßen war, das eben dieses Prinzip geschichtlicher Eigengesetzlichkeit aller Phänomene zu etablieren gesucht hatte. In Danzels Formulierung klingt bereits die spätere berühmte Formulierung Rankes an, eine jede Epoche stehe „unmittelbar zu Gott"“. Danzel hätte gewiß nicht so gesprochen: Gott war für ihn, wie sich aus dem ganzen hinterlassenen Werk ergibt, nicht zuletzt aus seinen Arbeiten über Lessing, kein wissenschaftlich brauchbarer Begriff. Aber der geschichtliche Eigenwert aller Erscheinungen - der staatlich-politischen bei Ranke, der lite- 
rarischen und künstlerischen bei Danzel - wird in beiden Fällen deutlich hervorgehoben. In seiner Studie über Goethes und Heinrich Meyers Kunstauffassung scheint Danzel durch die Art seiner Betrachtung von Hegel zu Ranke gewechselt zu haben. Wobei er, wie sogleich hinzugesetzt werden muß, den Übergang zur geschichtlichen Pragmatik durchaus nicht als Wendung zu einem politischen Konservativismus im Sinne Rankes oder der historischen Schule zu verstehen gedachte. Das zeigt sich gerade an diesem Aufsatz mit seinen vielen unmutigen Bemerkungen über die christlich-romantische Malerei der Nazarener.

Die Bedeutung der Studie liegt vor allem darin, daß Danzel die geschichtlich unkonkrete Ästhetik WINCKELmaNNs, wohl auch Lessings, erst recht der Weimarischen Kunstfreunde, historisch genauer zu situieren sucht. Dadurch gelangt er zu bemerkenswerten Erkenntnissen über die zeitgeschichtlichen Voraussetzungen im Verhältnis einzelner Kunstgattungen zueinander. Indem er mit Recht darauf hinweist, daß Winckelmann sein gesamtes ästhetisches System und die meisten seiner kunstgeschichtlichen Einsichten der antiken Skulptur abgewonnen habe, ohne dabei die Hilfsmittel seiner klassisch-philologischen Erziehung preiszugeben, sucht Danzel den Anachronismus der Goetheschen Kunsttheorie nachzuweisen. Als Anhänger Winckelmanns habe Goethe nicht bloß die Prinzipien der Plastik bei Beurteilung aller Malerei anzuwenden versucht, sondern überdies erkannt, daß die moderne bildende Kunst seiner eigenen Goethe-Zeit durchaus malerisch, gegenplastisch gewesen sei. Darum sei sein Verhältnis zur bildenden Kunst der eigenen Zeit nicht bloß anachronistisch gewesen, sondern eigentlich unkünstlerisch. Danzel geht noch weiter und gebraucht, wenn er von den Preisaufgaben der Weimarischen Kunstfreunde spricht, das Eigenschaftswort ,schulmeisterlich“. Bei Goethe, bei den Weimarischen Kunstfreunden, vor allem also Heinrich Meyer, nicht zuletzt auch bei der von Goethe so hochgeschätzten klassischen Philologie Friedrich August Wolfs erblickt Danzel ein verhängnisvolles „Abdestillieren des Geistes von dem Geschichtlichen“.

Trotzdem ist Danzel durchaus nicht blind gegenüber den Verschiedenheiten im Verhältnis Winckelmanns und Goethes 
zu den Werken der bildenden Kunst. Winckelmann sei weitgehend Theoretiker. Goethe aber betrachte alle Kunsttheorie als Ausgangspunkt praktischen Verhaltens. Ebensowenig möchte Danzel den Romantikern in ihrer Kritik an Goethe allzu weit folgen. Danzel ist kein Romantiker. Bemerkenswerterweise gibt es unter seinen Studien zur deutschen Literaturgeschichte keine einzige, die sich ausführlich mit romantischer Kunst und Literatur beschäftigt hätte. Bloß hier, wo es sich in der Tat, im Zusammenhang mit Goethes Winckelmannschrift von i 805 , um die Auseinandersetzung zwischen Klassik und Romantik handelt, geht der Interpret auch auf die romantischen Positionen ein. Sein Urteil über die Romantiker ist knapp formuliert und trifft weitgehend das Richtige. Ihr Verdienst liege darin, die Antike als geschichtlich einmalige Erscheinung verstanden zu haben: „Dies ist ihr historisches Verdienst, welches ihnen nicht abgesprochen werden darf. Die Bedeutung ihres Standpunktes ist eine vorwaltend literarhistorische und kritische, und als Literarhistoriker und Kritiker genießen sie allgemeine Anerkennung. Thre poetische Produktion dagegen ist freilich größtenteils durchaus verfehlt, aber sie ist es nur darum, weil sie ihre wissenschaftliche Tat in dieselbe übertrugen. " In sonderbarer Verkennung der geschichtlichen Zusammenhänge scheint Danzel dabei die Ästhetik ScHILlers in die Nähe des Romantischen rücken zu wollen, denn er behauptet geradezu, Schillers Begriff des Sentimentalischen sei zur Grundlage für die spätere romantische Ästhetik geworden. Goethe aber, der naive Dichter, habe die Gleichberechtigung sentimentalischer und erst recht romantischer Poesie eigentlich niemals wahrhaft anerkannt.

Der Schluß des Aufsatzes wirkt einigermaßen überraschend; er war nach den vorhergehenden Ausführungen nicht eigentlich zu erwarten. Danzel hatte Goethes ästhetische Positionen als typisch für das 18 . Jahrhundert bezeichnet; daraus mußte sich eine Art Donquijoterie der Weimarischen Kunstfreunde ergeben, und es sollte heute wohl auch nicht bestritten werden, $\mathrm{da} ß$ es sich weitgehend um Donquijoterie gehandelt hat. Die Antike als ästhetische Norm verstanden, nicht als geschichtliches Phänomen. Skulpturale Prinzipien auf die Malerei und überdies noch auf die Poesie übertragen. Festhalten an Ge- 
dankengängen des r8. Jahrhunderts, die - man denke an Montesqieu oder Gibbon - immer bloß die Frage nach den Ursachen von Aufstieg und Verfall der antiken Kultur untersucht hatten, statt sich mit der Einzigartigkeit dieser geschichtlichen Erscheinungen zu beschäftigen. Abstrakte Antithetik in der Entgegensetzung des Schönen und des Charakteristischen. Danzels Kritik kommt aus der Schule des historischen Denkens, ist also weitgehend durch die Romantik geprägt, übrigens natürlich auch durch Hegel, dessen Ästhetik sonderbarerweise in diesem Aufsatz allzu stark in die Nähe romantischer Kunstauffassung gerückt erscheint. Gegen Winckelmann wird gut hegelianisch eingewandt, kein Gegenstand in der Kunst könne an und für sich bedeutend sein, ,,sondern nur für den, der etwas aus ihm zu machen weiß“.

Die Rettung Goethes durch Danzel aber erfolgt auf den letzten Seiten des Aufsatzes dadurch, daß Goethe zwar als Ästhetiker und Kunsthistoriker verdammt, als Theoretiker der Literatur aber, erst recht natürlich als Dichter, losgesprochen wird. Der Künstler und Kunstkenner Goethe habe zwar die antike Skulptur und den Schönheitsbegriff Winckelmanns zu normieren versucht, glücklicherweise aber nicht daran gedacht, in ähnlicher Weise etwa den französischen Klassizismus für die deutsche Literatur als Norm zu verkünden. (Die Weimarer Inszenierungen französischer Tragödien durch Goethe zu Beginn des 19. Jahrhunderts scheint Danzel als bloße Konzession an den Herzog zu betrachten; Schillers für die Entwicklung der deutschen Klassik so wichtiges Gedicht »An Goethe, als er den Mahomet von Voltaire auf die Bühne brachte« kümmert den Interpreten dabei nicht.) So habe Goethe in seiner Dichtung das Charakteristische und das Schöne, die scheinbar so absoluten Gegensätze, zu neuer künstlerischer Einheit verbunden. Goethes Dichtung ist damit für Danzel gleichzeitig antik und modern. Diese Konklusion wirkt etwas überraschend; sie ist durch den Text des Aufsatzes nicht eigentlich begründet worden. Auch diese Studie ist ein Werk des Übergangs: nicht bloß von Hegel zu Ranke. Der Kunst- und Literaturhistoriker, voller Stolz auf das neue geschichtliche Denken, steht sehr kritisch zu den normativen Kunstprinzipien des I8. Jahrhunderts, ohne dabei zu berücksichtigen, daß sein eigenes ge- 
schichtliches Bewußtsein undenkbar ist ohne die Besinnungen Voltaires und Montesquieus, Herders und Justus Mösers auf die Gesetze der geschichtlichen Evolution. Aber auch eine Übergangssituation in Danzels Goethe-Interpretation läßt sich feststellen. Nur noch gelegentlich spielen die Kategorien der früheren Studie über Goethes Spinozismus bei der Analyse mit. Dafür bereitet sich, etwas abrupt, gegen Schluß der Betrachtung über das Winckelmann-Thema, eigentlich also über die Ästhetik der deutschen Klassik, schon jene Erkenntnis vor, die später in der Einleitung zum Goethe-Kommentar ausgesprochen wurde: daß sich in Goethes Poesie eine Synthese des Antiken und des Modernen finde: ein Zusammenklang aus geschichtlich einmaliger "Gelegenheit" und einer tieferen ästhetischen Gesetzlichkeit.

Bleibt in allen Wandlungen seines Goethebildes doch stets die tiefe Liebe zu Goethes Dichtung spürbar, so ist das Verhalten des Interpreten zu ScHILler weitaus kühler. Danzel ist weder ein Romantiker noch ein Jungdeutscher. Wenn Ludwig Börne sehr scharf mit Goethe ins Gericht ging, Schiller schon eher gelten ließ, so findet sich bei Danzel weitaus geringere Sympathie für Schiller. Schillers künstlerisches Schaffen vollends scheint Danzel nicht eben stark interessiert zu haben. Übrigens ist die Schiller-Interpretation durchaus nicht frei von Widersprüchen. In dem Aufsatz über die Weimarischen Kunstfreunde wird behauptet, bloß Goethe sei „durchaus als Schöpfer der deutschen Dichtung “ zu betrachten. Schiller habe sich lediglich „durchaus an der Anschauung von Goethes Werken und selbst von Goethes Persönlichkeit hinaufgerankt". Andererseits gipfelt die spätere Einleitung zum Goethe-Kommentar geradezu in einer scharfen ästhetischen Antithese zwischen Goethe und Schiller. Daß Danzel kein tieferes Verhältnis zu Schiller besaß und es ihm eigentlich etwas schwer wurde, dessen Werk im Gegensatz zu Goethe einigermaßen gerecht zu beurteilen, zeigt seine Studie "Über Schillers Briefwechsel mit Körner «. Die Attitüde findet ihren charakteristischen Ausdruck übrigens darin, daß Danzel in der sehr eindringlichen und gründlichen Studie über Schillers ästhetischen Briefwechsel mit Körner alle Aussagen über die eigentlichen Dichtungen beiseite läßt, um sich ausschließlich mit Schillers philosophischer 
Entwicklung und den inneren Widersprüchen seiner Ästhetik zu beschäftigen.

Dabei geht es ihm auch um eine Revision seiner eigenen früheren Darstellung der Schillerschen Ästhetik, die unter dem Titel "Über den gegenwärtigen Zustand der Pbilosopbie der Kunst und ibre näcbste Aufgabe» im Jahre 1844 in Fichtes >Zeitschrift für Philosophie und spekulative Theologieく veröffentlicht worden war. Hier hatte Danzel die Entwicklung von Schillers philosophischen Ideen an den Abhandlungen zu demonstrieren gesucht und war im übrigen bemüht gewesen, Schiller als Zwischenstufe zwischen Kant und Hegel zu verstehen. „Totalität ist das Losungswort der Schillerschen Sittenlehre", so weit ging damals die hegelianische Interpretierung Schillers durch Danzel. Die Veröffentlichung des Briefwechsels mit Körner mahnte den Ästhetiker jedoch zur Vorsicht. In seiner Rezension bekannte er von der eigenen früheren Abhandlung, sie sei „seit der Veröffentlichung des Körnerschen Briefwechsels als gänzlich antiquiert zu betrachten".

$\mathrm{Da}$ es sich hier darum handelt, Danzels Stellung als Literaturhistoriker genauer zu charakterisieren, wobei seine eigentliche Leistung im Bereich der philosophischen Ästhetik zurücktreten muß, kann auf eine Auseinandersetzung mit Danzels Kritik an Schillers ästhetischen Positionen verzichtet werden. Bemerkenswert bleibt die Feststellung, daß er in Schillers Ästhetik eine bedeutende philosophische, über Kant hinausführende Leistung zu erkennen glaubt und daß er, einige Modifizierung und Beseitigung innerer Widersprüche vorausgesetzt, die Grundprinzipien von Schillers Ästhetik als gültige Basis einer ästhetischen Gesetzlichkeit anzusehen scheint.

Für den Literarhistoriker bedeutsam ist der Hinweis auf die "Briefe über die ästhetische Erziehung des Menschen", die Danzel zwar ganz richtig als bloße Vorstufe zu Schillers Ästhetik bezeichnet, im übrigen aber als tiefste philosophische Analyse Schillers ansieht. Ebenso sachkundig und klug ist die Erkenntnis, die wichtigsten ästhetischen Grundprinzipien Schillers seien bereits vor der Auseinandersetzung mit Kant fixiert gewesen: gewisse Thesen aus dem Gedicht "Die Künstler" habe auch der Kantianer Schiller niemals preisgegeben. Ist das aber richtig, so wird man der ziemlich schnöden Bewertung 
Körners durch Danzel widersprechen müssen, wonach Körner eigentlich niemals über die „objektive Ästhetik“ Baumgartens hinausgelangt sei. Allein in den "Künstlern" steckt auch der Ästhetiker Baumgarten, und er findet sich noch in Schillers späteren Schriften trotz aller Lektüre einer »Kritik der Urteilskraft $\ll$.

Sehr bemerkenswert sind Danzels Analysen der ästhetischen Gegensätze zwischen Schiller und Goethe bei aller scheinbaren Übereinstimmung. Das wird so ausgedrückt: „Nichtsdestoweniger aber blieb der eine Naturalist und der andere Kantianer -, denn Goethe hält die Erscheinung für wirklich frei - wie er ihr denn ja in der Idee der Metamorphose ein eigenes Leben und eine eigene Geschichte zuschreibt -, Schiller läßt dies aber nur für das gemeine Bewußtsein gelten, das freilich nicht inne wird, daß die Freiheit nur eine geliehene ist." Gegen den Schluß des Aufsatzes erleben wir freilich einen Rückfall in die hegelianische Terminologie, denn diesmal wird Schillers ästhetischer Zentralbegriff im Sinne der „Totalität““ interpretiert.

Der Rest des Briefwechsels scheint Danzel nicht mehr zu interessieren. Als Schiller von der philosophischen Spekulation wieder „ganz zur Produktion zurückgekehrt ist“, wird Körner zwar, wie Danzel etwas gönnerhaft zugibt, zu einem selbständigeren Briefpartner des Freundes, aber der Rezensent hat nun das Interesse am Thema verloren. Der Ästhetiker Schiller war ihm wichtig, zum Dichter Friedrich Schiller scheint Danzel kein tieferes Verhältnis gehabt zu haben.

Das nimmt nicht wunder, macht man sich Umfang und Bedeutung seiner Shakespeare-Studien klar. Wahrscheinlich wäre es Danzel, hätte er länger leben und schaffen können, durchaus möglich gewesen, in den erbitterten ästhetischen Diskussionen zur Dramaturgie inDeutschland, die alle um das Thema Schiller oder Shakespeare kreisten, eine Klärung der Begriffe vorzunehmen. Sein ungeheures Wissen, sein Fleiß, die Schärfe seines Denkens, nicht zuletzt sein sonderbar spröder hanseatischer Humor hätten die Behandlung eines Themas gefördert, das von Büchner bis zum jungen Gerhart Hauptmann aus der Entwicklung der deutschen Dramatik und Dramaturgie im 19. Jahrhundert nicht weggedacht werden kann. Die Studie "Shake- 
speare und noch immer kein Ende « aus Danzels letztem Lebensjahr I 850 (auch sie erschien in den >Blättern für litterarische Unterhaltung () besitzt nicht bloß gelockerten Stil, eine anschaulichere und weniger monologische Art der Darstellung, sondern vor allem alle Entschlossenheit des Literaturhistorikers, dem abstrakten Spekulieren und Moralisieren vor Werken der Poesie mit der Forderung nach Bewertung eines jeden Kunstwerks nach seinen eigenen inneren Gesetzen und nach den geschichtlichen Bedingungen seiner Entstehungszeit entgegenzutreten.

Aus profunder Sachkenntnis gibt Danzel, der sich diesmal das Shakespeare-Werk des Hallenser Professors Hermann Ulrici zum Anlaß genommen hat, zunächst einen Rückblick auf den Prozeß, den Gundolf im 20. Jahrhundert unter dem Titel "Shakespeare und der deutsche Geist" auf seine Art nachzuzeichnen versuchte. Auch Danzel beginnt mit einer Charakteristik der verschiedenen Phasen deutscher Shakespearerezeption. Zustimmend beruft er sich, ohne den Namen des Verfassers zu nennen, auf Adolf Stahrs Analyse des Problems "Shakespeare in Deutschland", die 1834 in dem von Robert Prutz herausgegebenen $>$ Literarhistorischen Taschenbuch erschienen war. Übrigens beginnt Danzel nicht bei Lessing, sondern erst beim Sturm und Drang: Enthusiasmus und Mißverständnis, mehr glaubt er dort nicht entdecken zu können. Ebenso wird bestritten, die Romantiker hätten mit ihrem Shakespearekult zum tieferen Verständnis des englischen Dramatikers beigetragen. Danzel benutzt die Gelegenheit - seine Nebenbemerkungen sind oft eindringlicher und tiefer als die Hauptgedanken -, höchst dezidiert zu erklären, er halte insgesamt die Begriffe des Romantischen, des Phantastischen und der Ironie, so wie sie von der romantischen Schule präsentiert wurden, für unschlüssig. Man habe sich bisher im wesentlichen bloß Shakespeares bedient, statt den Versuch zu machen, ihn zu verstehen. „Wir haben aber bis jetzt in bezug auf Shakespeare nur auf demselben Standpunkte gestanden wie die Renaissancekünstler aller Art in bezug auf das Altertum - das war es, was ich zu beweisen hatte."

Was nun zu geschehen habe? Danzel versucht es gut hegelianisch aus der Negation zu entwickeln, indem er an ULRICIs Shakespeare-Buch zu zeigen bemüht ist, wie man es nicht 
machen dürfe. Ulrici wird zwar gelobt, ,in bezug auf Shakespeare die historischen Bezüge zuerst mit wissenschaftlichem Ernst ins Auge gefaßt zu haben“. Dann aber wird ihm trotzdem ein Rückfall in die „Grillen und Schrullen der romantischen Willkür" zum Vorwurf gemacht. Nun dringt in der Polemik gegen Ulrici sogar der bürgerlich-liberale Standpunkt durch, denn Ulrici habe bei seinem Bemühen, vor Shakespeares großen Tragödien jeweils mit den Kriterien von Schuld und Sühne zu arbeiten, unversehens die Prinzipien der Feudalität übernommen. Am Beispiel des Königs Lear wird das demonstriert: „Aber es scheint, als wenn in Ulricis Rechtsphilosophie die hocharistokratischen Hausgesetze als absolut vernünftig deduziert werden, wie in einer anderen die Majorate, und Romeo und Julia sind freilich beide von Adel." Das macht: „Ulrici steht überhaupt den Romantikern so gar fern durchaus nicht." Sein Epigonentum bringe ihn um die Früchte eigener Forschung. Der Versuch, in Shakespeares Dramen eine in sich geschlossene „Weltanschauung“ entdecken zu wollen, bedeute Verkennung der spezifischen ästhetischen Prinzipien, opfere die Autonomie des Kunstwerks einer wie immer gearteten Heteronomie der Zwecke. Nun entwickelt Danzel die Grundprinzipien seiner literaturwissenschaftlichen Methode. Alles komme darauf an, das Kunstwerk in seinen besonderen Daseinsbegriffen zu erfassen. Der Zweck des Kunstwerks liege in ihm selber. Alles andere führe zu Gewaltsamkeiten und Mißverständnissen. Der „Gedanke“ des Kunstwerks sei das Kunstwerk selbst. Alles übrige bedeute Fetischismus. Danzel findet einen bezaubernden Vergleich: „Was der Mensch liebt, das schmückt er mit dem Besten, was er hat. Behängt der Wilde seinen Götzen mit Glasperlen und Flittergold, so mag auch wohl der Philosoph seinen Lieblingsdichter mit spekulativistischen Ideen behängen. Aber warum mußte diese liebenswürdigste aller Menschlichkeiten gerade an der Dichtkunst ausgeübt werden?“،

Um derlei Fehlschläge zu vermeiden, sieht Danzel als Literaturhistoriker nur zwei Möglichkeiten. Die eine habe zu zeigen, wie das Werk in seiner besonderen Gesetzlichkeit entstand. Hier scheint die Beziehung zwischen vorgeformtem Stoff und späterer Formung durch den Dichter besonders wichtig zu sein. Man erinnert sich daran, daß Danzel in seinen Analysen 
des Clavigo und der Iphigenie genau nach diesem Grundsatz vorgegangen war. An zweiter Stelle zu leisten sei bei Behandlung der Dichter und ihrer Werke ,die Einreihung derselben in ihrer Totalerscheinung in einen historischen Zusammenhang “. Das ist die methodologische Folgerung, die Danzel in seiner letzten Lebenszeit aus allen früheren Bemühungen um eine philosophisch-spekulative Betrachtung von Kunstwerken zieht.

Bleibt die Frage nach der geschichtlichen Deutung dieses jeweiligen historischen Zusammenhangs. Wie ist er zu verstehen? Gibt es Gesetzlichkeiten, die dem Literaturhistoriker erlauben, auch die eigene Zeit und das eigene Forschen als geschichtliches Moment zu verstehen? Auf diese Frage hatte Danzel schon am II. September I 849 mit jener Rede zu antworten gesucht, die er als Leipziger Privatdozent als Dank für Verleihung des Ernestischen Stipendiums vor Dekan und Pedellen gehalten hatte. Das Thema lautete: "Über die Bebandlung der Geschichte der neueren deutschen Literatur". In ihr wurde zum erstenmal versucht, die von Goethe theoretisch als allgemeine ästhetische Grundsätze formulierten Gedanken über die Beziehungen der deutschen Literatur zu den außerdeutschen $\mathrm{Na}$ tionalliteraturen konkret und historisch an der Geschichte der deutschen Literatur zu demonstrieren. Danzel mußte der immer noch in Deutschland nachwirkenden nationalistischen Beschränktheit entgegentreten, wonach sich die deutsche Literatur im wesentlichen autark und selbstgefällig verhalten könnte. Er mußte aber gleichzeitig gegenüber den gesellschaftlich fortgeschritteneren Nachbarvölkern, besonders den Engländern und Franzosen, mit Nachdruck die weltgeschichtliche und weltliterarische Bedeutung der deutschen Nationalliteratur hervorheben. Damit ging er einen wesentlichen Schritt über Goethe hinaus, der sein Schaffen in den Dienst deutscher künstlerischer Selbstbehauptung gestellt hatte und im Alter gegen Geister aufzutreten gezwungen war, die er selbst gerufen hatte. Danzel sieht sich wieder vor einem Augenblick des Neubeginns auf erhöhter geschichtlicher Stufe: er muß nun im Bereich der Weltliteratur die besondere Bedeutung deutscher Nationalliteratur fü $r$ diese Weltliteratur hervorheben. „Was man in der neueren Zeit herbeigewünscht hat, eine Weltliteratur, hat im 
Grunde seit mehreren Jahrhunderten bereits bestanden: ein wechselseitiger Austausch zwischen den verschiedenen Nationalliteraturen und ein gemeinsamer Boden, auf welchem sie alle miteinander standen. Nur daß gerade die deutsche Literatur sich zu Anfang bei diesem Austausch bloß empfangend verhalten hat - aber um so mehr ruht sie auf jenem Boden, desto mehr ist in ihr fast alles aus den Eigenschaften dieses letzteren und der Nahrung, die sie aus ihm gezogen, herzuleiten."

Dann folgen Sätze, in denen, bei aller Mäßigung im Ausdruck und wohl auch bei aller Zurückhaltung des Hamburgers, die Sprache eines Deutschen vernehmbar ist, der stolz von der unvergeßlichen und unvergleichlichen Wirkung der großen Dichter und Denker auf die Weltliteratur ihrer Zeit zu berichten weiß: „Wenn diese Literatur ihrem Ursprung nach nicht bloß eine deutsch-nationale ist, so bezeichnet ihr Auftreten auch nicht bloß eine Epoche in der Geschichte der deutschen Literatur, sie hat eine welthistorische Bedeutung: jene Weltliteratur selbst, auf welcher sie beruht, bekommt durch sie eine neue Richtung." Diese welthistorische Themenstellung der deutschen Nationalliteratur versteht Danzel als Befreiungs- und Emanzipationsfunktion. Worauf die merkwürdigen, gleichzeitig tiefdringenden und auch historisch beengten Sätze angefügt werden: „... und da hat denn nun die deutsche Literatur die Aufgabe gehabt, infolge mancher Anlässe in Frankreich und England, eine solche Befreiung auf ästhetischem Gebiete zu vollführen, während die religiösen und politischen Befreiungsversuche größtenteils den Engländern und Franzosen anheimfielen. " Hieß es doch etwa vier Jahre vor dieser Leipziger Rede in einem Aufsatz des jungen KarL MARx, ursprünglich auch einem Freunde von Danzels Lehrer Arnold Ruge, nämlich in der »Einleitung zur Kritik der Hegelschen Rechtsphilosophie«: „Die Deutschen haben in der Politik gedacht, was die anderen Völker getan haben. Deutschland war ihr theoretisches Gewissen... ... Wie die alten Völker ihre Vorgeschichte in der Imagination erlebten, in der Mythologie, so haben wir Deutsche unsere Nachgeschichte im Gedanken erlebt, in der Philosophie."

Aber hier bereits scheiden sich die Wege der beiden Altersgenossen vom Jahrgang I 8 I 8 . Theodor Wilhelm Danzel bleibt 
der deutsche Gelehrte, der Tatsachen konstatiert, Zusammenhänge überschaut, im letzten aber selbst aller Einwirkung auf den Geschichtsablauf entsagt. Ihm genügt die Erkenntnis einer welthistorischen Bedeutung der deutschen Nationalliteratur. Der junge Marx dagegen konstatiert den Anachronismus zwischen deutschen Geistestaten und unwürdigen deutschen $\mathrm{Zu}-$ ständen, um die Forderung zu stellen, diese Zustände in Form gesellschaftlicher Umgestaltung auf die Höhe deutscher Geistestaten zu heben.

Dem Umfang nach schmal ist das Werk, das der Ästhetiker, Literaturhistoriker und Kritiker Theodor Wilhelm Danzel hinterließ. Die Literaturforschung sah allzu lange das eigentliche Verdienst Danzels bloß in dem großen Wurf seiner LessingBiographie und in der Edition von Gottscheds Briefwechsel. Bei allem Wert, den diese Publikationen eines gediegenen Forschers besaßen, wird man aber die eigentliche Bedeutung Danzels in seinen Aufsätzen zur klassischen Literatur und Philosophie in Deutschland, insbesondere zu den Themen Goethe und Shakespeare, erblicken müssen. Hier äußert sich nicht bloß ein bedeutender Geist, sondern auch ein Forscher, den seine philosophischen Anfänge in besonderem Maße befähigen sollten, methodische Probleme der Literaturwissenschaft zu erörtern, die im Übergang vom Hegelianismus zum Positivismus $z$ war einer konkreten geschichtlichen Situation angehörten, im übrigen aber bis heute nichts an Bedeutung verloren haben. Darum ist Theodor Wilhelm Danzel weit mehr als eine „abgelebte Gestalt"،, um es mit Hegels Worten zu sagen. Das wird sich, wie zu hoffen steht, erweisen, wenn seine wichtigsten Arbeiten zur deutschen Literaturgeschichte nach mehr als einem Jahrhundert vor neuen Lesern nun erneut zum Problem werden können. 
Theodor Wilhelm Danzel

AUFSÄTZE

ZUR LITERATUR UND PHILOSOPHIE

DER GOETHEZEIT 